\title{
HAMARTOMA FIBROANEXIAL EM CADELA - RELATO DE CASO
}

\author{
Fábio Ranyeri Nunes Rodrigues ${ }^{1}$ \\ Carlos Eduardo Bastos Lopes ${ }^{2}$ \\ Magna Gomes de Matos ${ }^{3}$ \\ Samantha Pinheiro Pimentel ${ }^{4}$ \\ Erika Carvalho de Alencar ${ }^{5}$ \\ Talles Monte de Almeida ${ }^{6}$ \\ Daniel de Araujo Viana ${ }^{7}$
}

RODRIGUES, F. R. N.; LOPES, C. E. B.; MATOS, M. G. de; PIMENTEL, S. P.; ALENCAR, E. C. de; ALMEIDA, T. M. de; VIANA, D. de A. Hamartoma fibroanexial em cadela. Arq. Ciênc. Vet. Zool. UNIPAR, Umuarama, v. 21, n. 1, p. 37-41, jan./mar. 2018.

RESUMO: A pele é o maior órgão do corpo do animal, atuando como uma barreira entre o meio externo e interno e suas afecç̧ões perfazem a média de $30 \%$ de todo atendimento clínico realizado em pequenos animais. Dentre as lesões não neoplásicas, encontram-se os hamartomas, que são oriundos de um crescimento excessivo de células e tecidos normais no local em que naturalmente se encontram, podendo ocorrer em qualquer tecido ou órgão. $\mathrm{O}$ hamartoma fibroanexial pode se apresentar como nódulo solitário, firme, circunscrito, séssil ou de aspecto polipoide, com ou sem alopecia parcial e ulceração. Os anexos cutâneos que se destacam nesse tipo de hamartoma são os folículos pilosos e as glândulas sebáceas, podendo aparecer em aspectos normais ou bizarros, como os folículos pilosos císticos rodeados por lóbulos sebáceos. O objetivo do presente trabalho foirelatar um caso de hamartoma fibroanexial em uma cadela sem padrão racial definido, de aproximadamente sete anos que foi levada à Unidade Hospitalar Veterinária da Universidade Estadual do Ceará (UECE), devido à presença de nódulo em região distal lateral do membro pélvico direito com crescimento lento e progressivo durante um ano. A paciente foi encaminhada para exames complementares de citologia e pré-cirúrgicos. Após excisão cirúrgica, o nódulo foi enviado para avaliação histopatológica. Microscopicamente, a lesão exibiu uma estrutura nodular intradérmica composta por tecido fibroso abundante, envolvendo e segmentando estruturas anexiais incompletas, representadas por glândulas sebáceas e folículos pilosos, alguns destes rôtos, suscitando intenso processo inflamatório piogranulomatoso. Os achados macro e microscópicos foram determinantes para o diagnóstico da lesão como hamartoma fibroanexial.

PALAVRAS-CHAVE: Anexos cutâneos. Canino. Pele. Tumor.

\section{FIBROADNEXAL HAMARTOMA IN A BICTH - CASE REPORT}

\begin{abstract}
Skin is the largest organ of the animal body, acting as a barrier between the external and internal environment, and infections to it consisting of an average $30 \%$ of all clinical care performed. Hamartomas are among the non-neoplastic lesions in the skin, originating from an excessive growth of normal cells and tissues in the place they are naturally found, which can take place in any tissue or organ. Fibroadnexal hamartoma may be presented as solitary, firm, circumscribed, sessile or polyp-like nodules, with or without partial alopecia and ulceration. The adnexal structures mostly observed are hair follicles and sebaceous glands, with normal or bizarre structures, such as cystic hair follicles surrounded by sebaceous lobes. This study has the purpose of reporting a case of fibroadnexal hamartoma in a 7-year-old bitch taken to the Veterinary Hospital of the State University of Ceará (UECE) due to a nodule in the lateral distal region of the right pelvic limb with slow and progressive growth over one year. The patient was referred to cytology and pre-surgical examinations. After surgical excision, the nodule was sent for histopathological evaluation. Microscopically, the lesion exhibited an intradermal nodular structure composed of abundant fibrous tissue, involving and segmenting incomplete adnexal structures, represented by sebaceous glands and hair follicles, some of these ruptured, leading to intense piogranulomatous inflammatory reaction. Macro- and microscopic findings were determinant for diagnosing this lesion as a fibroanexial hamartoma.
\end{abstract}

KEYWORDS: Canine. Cutaneous adnexa. Skin. Tumor.

\section{HAMARTOMA FIBROANEXIAL EN PERRA - RELATO DE CASO}

RESUMEN: La piel es el órgano más grande del cuerpo del animal y actúa como barrera entre el ambiente externo e inter-

DOI: 10.25110 /arqvet.v21i1.2018.6390

${ }^{1}$ Estudante de Graduação em Medicina Veterinária, Universidade Estadual do Ceará, CE, 60.714.903, Brasil. E-mail: frnr.mv@gmail.com ${ }^{2}$ Estudante de Graduação em Medicina Veterinária, Universidade Estadual do Ceará, CE, 60.714.903, Brasil. E-mail: 1993carlos.eduardo@gmail.com ${ }^{3}$ Estudante de Graduação em Medicina Veterinária, Universidade Estadual do Ceará, CE, 60.714.903, Brasil. E-mail: magna.gmatos@gmail.com ${ }^{4}$ Estudante de Graduação em Medicina Veterinária, Universidade Estadual do Ceará, CE, 60.714.903, Brasil. E-mail: samthvet@hotmail.com ${ }^{5}$ Médica Veterinária, Graduada, Universidade Estadual do Ceará, CE, 60.714.903, Brasil. E- mail: erikacarvalhodealencar@yahoo.com

${ }^{6}$ Doutor em Biotecnologia da Saúde - RENORBIO - Universidade Estadual do Ceará e Diretor Técnico-Científico Laboratório PATHOVET - Anatomia Patológica e Patologia Clínica S/S LTDA (http://www.pathovet.com.br). E-mail: viana.daniel78@gmail.com

${ }^{7}$ Médico Veterinário. Especialização em Patologia Veterinária. Especialização em Clínica e Cirurgia de Pequenos Animais. Especialização em Medicina Veterinária Legal. Mestre em Patologia. Doutor em Biotecnologia da Saúde - Tese na área de Patologia Veterinária. Coordenador da Associação Brasileira de Medicina Veterinária Legal. 
no, representando un promedio del 30\% de toda la atención clínica realizada en pequeños animales. Entre las lesiones no neoplásicas se encuentran los hamartomas, que se originan a partir de un crecimiento excesivo de células y tejidos normales al lugar donde ocurren naturalmente, pudiendo ocurrir en cualquier tejido u órgano. El hamartoma fibroanexial puede presentarse como nódulos solitarios, firmes, circunscritos, sésiles o en forma de pólipos, con o sin alopecia parcial y ulceración. Las estructuras anexas más vistas son los folículos pilosos y las glándulas sebáceas, que aparecen en aspectos normales o anormales, como los folículos pilosos císticos rodeados de lóbulos sebáceos. El objetivo del presente estudio ha sido relatar un caso de Hamartoma fibroanexial en una perra sin patrón racial de aproximadamente siete años que fue llevada al Hospital Veterinario de la Universidad Estatal de Ceará (UECE), debido a un nódulo en la región distal lateral del miembro pélvico derecho con crecimiento lento y progresivo de un año. La paciente fue enviada para citología y los exámenes pre quirúrgicos. Después de la extirpación quirúrgica el nódulo fue enviado para evaluación histopatológica. Microscópicamente, la lesión exhibió una estructura nodular intradérmica compuesta de abundante tejido fibroso, involucrando y segmentando estructuras anéxales incompletas, representadas por glándulas sebáceas y folículos pilosos, algunas de ellas rotas, provocando intenso proceso inflamatorio piogranulomatoso. Los hallazgos macroscópicos y microscópicos fueron determinantes para el diagnóstico de la lesión como hamartoma fibroanexial.

PALABRAS CLAVE: Anexos cutáneos. Canino. Piel. Tumor.

\section{Introdução}

A pele é o maior órgão do corpo do animal e atua como uma barreira entre o meio externo e interno e suas afecções podem perfazer a média de $30 \%$ de todo atendimento clínico realizado no meio veterinário (MEIRELES et al., 2013). Lesões palpáveis podem ser de origem neoplásica e não neoplásica, sendo as primeiras de maior ocorrência, podendo perfazer até $63 \%$ das lesões observadas em cães (BORGES et al., 2016). Dentre as não neoplásicas, encontram-se os hamartomas, os quais são lesões tumorais oriundas de um crescimento excessivo de estruturas normais ao local em que naturalmente se encontram, a qual pode ocorrer em qualquer tecido ou órgão (GROSS et al., 2005). O hamartoma fibroanexial compreende em torno de 2,7\% das lesões cutâneas em cães, a qual também pode ser chamada de displasia anexial focal, nevo anexial ou displasia fibroanexial e se assemelha ao hamartoma folículo-sebáceo cístico que ocorre em humanos (LIN; TSAI, 2000; SCOTT et al, 2001). Além deste, existem os hamartomas foliculares, colagenosos, sebáceos, apócrinos, lipofibromatoso, epidérmico e o fibroepitelial (GOLDSCHMIDT; SHOFER, 1992; SCOTT et al., 2001; GROSS et al., 2005; SIPOS et al., 2007; LOURES; CONCEIÇÃO, 2009; MEIRELES et al., 2013).

Macroscopicamente, pode-se apresentar como nódulos solitários, firmes, circunscritos, sésseis ou de aspecto polipoide, com ou sem alopecia parcial e ulceração (LIN; TSAI, 2000; SCOTT et al., 2001; GROSS et al., 2005). Suas características histopatológicas, compreendem uma desordem hiperplásica de anexos cutâneos associados ao tecido conectivo fibroplásico circunjacente (GROSS et al., 2005; LOURES, 2005). Os anexos cutâneos que se destacam nesse tipo de hamartoma são os folículos pilosos e as glândulas sebáceas, podendo aparecer em aspectos normais ou bizarros, como os folículos pilosos císticos rodeados por lóbulos sebáceos (EL-DAROUTY et al., 2001; GROSS et al., 2005; LOURES, 2005).

Sua etiologia é controversa, pois pode ser considerada congênita, mesmo que as lesões não sejam vistas ao nascer, proliferando e manifestando clinicamente mais tardiamente, ou adquirida, decorrente de um trauma crônico que pode levar a uma proliferação reativa e consequente displasia dos anexos cutâneos (GOLDSCHMIDT; SHOFER, 1992; EL-DAROUTY et al., 2001; GROSS et al., 2005; BOYLE; HILL, 2014; MAXIE et al., 2016).
Assim, o objetivo do presente trabalho foi relatar um caso de hamartoma fibroanexial em uma cadela, buscando disponibilizar na literatura esse tema que ainda se encontra escasso no âmbito da medicina veterinária.

\section{Relato de Caso}

Uma cadela, sem padrão racial definido, de aproximadamente sete anos foi levada à Unidade Hospitalar Veterinária (UHV) da Universidade Estadual do Ceará (UECE), devido à presença de nódulo solitário pruriginoso na região lateral do membro pélvico direito com crescimento lento e progressivo por aproximadamente um ano, exofítico, alopécico, enegrecido, firme e de aspecto polipoide (Figura 1A).

O paciente foi encaminhado para exames completares de citologia e pré-cirúrgicos. O exame de citologia foi realizado segundo técnica descrita por Cowell et al. (2009), que consiste na aspiração de amostra citológica do nódulo a partir de uma agulha fina acoplada a uma seringa, na qual foi aplicada uma pressão negativa no momento do deslocamento do êmbolo, levando as células da massa ao bisel da agulha, dispondo o conteúdo em lâminas, corando-as com o kit de coloração citológica Panótico Rápido ${ }^{\circledR}$. Posteriormente, o material foi avaliado com auxílio de microscopia óptica, na qual foi observado quadro citológico compatível com inflamação piogranulomatosa, composta por neutrófilos íntegros e degenerados, macrófagos ativados, linfócitos e fibroblastos reativos, adjuntos a debris celulares (Figura 1C).

Após excisão cirúrgica do nódulo, o mesmo foi conservado em formalina à $10 \%$ e enviado para avaliação histopatológica no laboratório PATHOVET - Anatomia Patológica e Patologia Clínica Veterinária S/S LTDA, localizado na cidade de Fortaleza-CE (http://www.pathovet.com.br). O nódulo possuía aproximadamente 5,0 x 4,0 x 3,0 cm, incompletamente lobulado ao corte com múltiplas pequenas cavitações e aspecto fibroso (Figura 1B). Fragmentos da lesão selecionados em análise macroscópica prévia foram desidratados em sucessivas diluições crescentes de etanol para posterior diafanização, parafinização, inclusão e cortes em micrótomo na espessura de $4 \mu \mathrm{m}$. Em seguida, procedeu-se a coloração de Hematoxilina e Eosina (HE) e análise em microscopia óptica (TIMM, 2005).

As secções histopatológicas mostraram lesão nodular intradérmica composta por tecido fibroso abundante (fibroplasia) com áreas de degeneração mixóide, que envolve 
e segmenta estruturas anexais hiperplásicas e de maturação incompleta, representadas por glândulas sebáceas e folículos pilosos dilatados, alguns destes rôtos, suscitando intenso processo inflamatório piogranulomatoso (figura 1D, 1E, 1F), concluindo o diagnóstico como Hamartoma Fibroanexial. Até o presente momento, a excisão cirúrgica foi curativa, pois não houve recidiva relatada pelo proprietário.

Figura 1: A. Lesão polipoide na região lateral do membro pélvico direito de uma cadela SRD com sete anos; B. Aspecto macroscópico da lesão exibindo superfície de corte com evidente multilobulação e cavitações e aspecto fibroso; C. Fotomicrografia de amostra citológica exibindo infiltrado inflamatório piogranulomatoso constituído por macrófagos, neutrófilos íntegros e degenerados (Panótico Rápido, 400x); D. Fotomicrografia das secções histopatológicas evidenciando múltiplos lóbulos sebáceos e um folículo piloso cístico com queratina em seu interior (HE, 200x); E. Fotomicrografia das secções histopatológicas demonstrando os inúmeros lóbulos sebáceos associados a folículos envoltos por estroma fibroso com áreas de degeneração mixóide (seta) (HE, 200x), e maior abundância em fibroplasia intensa (seta) (F) (HE, 200x).
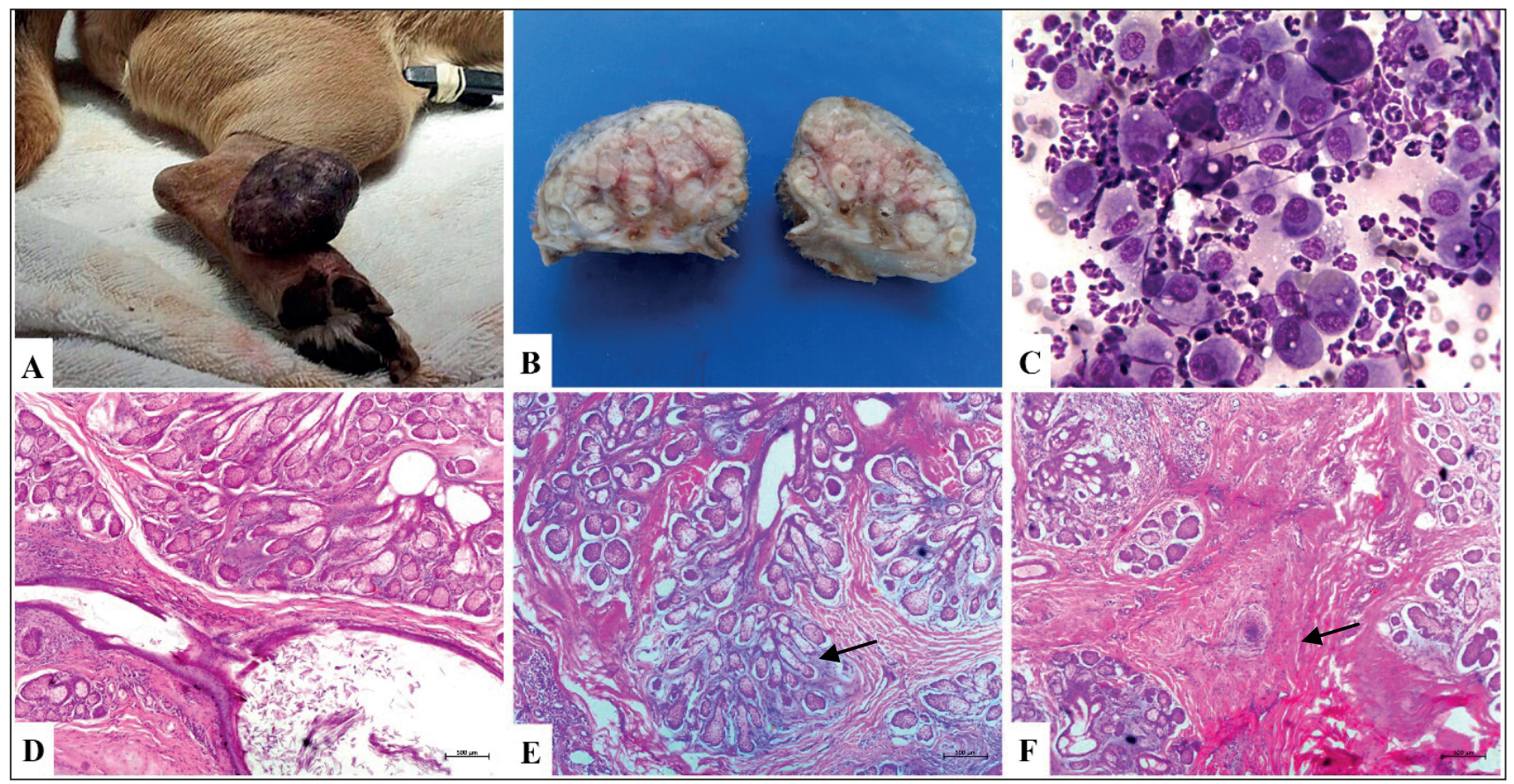

\section{Discussão}

Nódulos cutâneos únicos e múltiplos são frequentes em cães e sua apresentação e etiologia pode variar bastante entre seus diferentes tipos (JOYCE, 2010; MILLER et al., 2013). Os hamartomas são considerados lesões nodulares não neoplásicas e primariamente não inflamatórias (MILLER et al., 2013). De acordo com um estudo feito por Chikweto et al. (2011), em Granada, na América Central, o hamartoma se apresentou como a forma mais comum de lesão não neoplásica em cães $(28,5 \%)$, contudo outros autores consideram seu aparecimento raro (GROSS et al., 2005; GOLDSCHIMIDT; GOLDSCHIMIDT, 2017).

No Brasil, a situação é semelhante àquela considerada na literatura internacional e há poucos relatos de hamartoma fibroanexial ou quaisquer um dos outros subtipos de hamartomas (LOURES; CONCEIÇÃO, 2009; MEDEIROS et al., 2014).

A idade média para o aparecimento da alteração em questão varia de cinco a 12 anos (GOLDSCHMIDT; SHOFER, 1992), mas Loures e Conceição (2009) afirmam ser de 6,3 anos a média aproximada de idade para o aparecimento do tipo de hamartoma (fibroanexial) no referido estudo, o que não difere do encontrado no presente caso, com aparecimento ou deflagração da lesão em animal adulto.

Diversos autores discutem acerca da possível etio- logia para o processo, atribuindo-a à alterações congênitas ou mesmo a reações inflamatórias crônicas, além da participação de outros fatores como a própria predisposição racial e idade (GROSS; IHRKE; WALDER, 1992; GOLDSCHMIDT; SHOFER, 1992; EL-DAROUTY et al., 2001; GROSS et al., 2005; BOYLE; HILL, 2014; MAXIE et al., 2016).

Entretanto, pouco ainda se conhece sobre a verdadeira relevância de fatores como sexo, raça e idade no aparecimento dos hamartomas, ou ainda se, na verdade, outros elementos possam estar diretamente associados a sua origem, como o clima e exposição solar (CHIKWETO et al., 2011), ou mesmo o padrão de tamanho do pelo, pois, conforme estudado por Gross et al. (1992), acredita-se que cães de pelo longo possuam maior predisposição para o desenvolvimento de neoplasias foliculares, posto que nesses animais a fase de crescimento piloso anagênica esteja em constante ocorrência. Contudo, no presente caso, o padrão de cobertura pilosa do animal em questão se constituía por ser do tipo curto.

No presente caso não se pode correlacionar o aparecimento do hamartoma com a raça do animal ou com o tipo de pelo que apresenta, uma vez que neste caso, o cão não apresentava padrão racial definido e possuía padrão de cobertura pilosa do tipo curto. Vale ressaltar, contudo, que o fator de exposição solar pode ser associado, uma vez que o animal era oriundo da cidade de Fortaleza, no Nordeste brasileiro, onde a exposição solar é alta e a média de radiação global é a 
maior do Brasil (PEREIRA et al., 2006).

Com relação à caracterização macroscópica, alguns fatores aqui observados, como a presença de nódulo único e solitário, prurido, bem como sua aparência exofítica, estão de acordo com os dados avaliados por Loures e Conceição (2009), onde em um levantamento de 81 casos de nevos e hamartomas cutâneos, os hamartomas fibroanexiais foram os de maior prevalência, sendo de $92 \%$ a apresentação como nódulos únicos, $96,3 \%$ como exofíticos e $56 \%$ como pruriginosos.

Ainda, o tamanho da lesão, bem como o aspecto polipoide e alopécico do nódulo descrito neste relato são semelhantes aos descritos na literatura, onde Scott et al. (2001) e Gross et al. (2005) descrevem os nódulos de hamartomas fibroanexiais como massas em forma de cúpula ou polipoide, variando de um centímetro a mais de quatro centímetros de diâmetro, e que apresentam, frequentemente, alopecia parcial ou total, similarmente à variação de tamanho encontrada no levantamento feito por Loures e Conceição (2009), a qual foi de 0,5 a $8,0 \mathrm{~cm}$ de diâmetro.

O exame de citologia se constitui por ser um do tipo rápido, de baixo custo, minimamente invasivo e muitas vezes eficaz, haja vista as próprias limitações deste método, já que, diferentemente da histopatologia, não avalia arquitetura tecidual, mas, principalmente, células isoladas. Portanto, considera-se a citologia uma ótima ferramenta de triagem (COWELL et al., 2009; RASKIN; MEYER, 2011).

Para o caso em estudo, o exame citológico nos forneceu o conhecimento da ocorrência de um intenso processo piogranulomatoso associado à fibroblastos reativos e matriz colagenosa, além da presença de sebócitos, possibilitando a inicial suspeita de envolvimento de anexo cutâneo. No entanto, o referido exame não foi suficiente para o estabelecimento do diagnóstico definitivo, talvez por alguns elementos que dificultaram a avaliação aqui apresentada: a própria dimensão da lesão, o que pode impossibilitar a total representatividade da lesão; a hemodiluição da amostra, oriunda de contaminação sanguínea agravada pela manipulação tecidual na colheita por agulha fina; a contaminação por células inflamatórias relacionadas com o processo de ruptura de folículos císticos, muitas vezes causando reatividade do tecido circunjacente; e o caráter compacto da lesão aliado a sua natureza fibrosa, possibilitando escassa esfoliação de material.

De acordo com Scott et al. (2001), Gross et al. (2005) e Kiehl e Mays (2016), os folículos císticos preenchidos por material queratinizado podem romper e iniciar uma resposta inflamatória de corpo estranho, caracterizada por inflamação piogranulomatosa, corroborando assim para o tipo de infiltrado encontrado, tanto no exame citopatológico, como no histopatológico do presente relato.

Como possível embargo, a literatura afirma que a diferenciação entre o hamartoma fibroanexial e outros crescimentos benignos do epitélio basal, sendo esses neoplásicos ou não, como o cisto epidermóide, pode ser difícil ou até mesmo impossível à nível citológico, haja vista que em ambos poderia ocorrer a visualização de escamas córneas e células do tecido conectivo reativas, além de infiltrado inflamatório por vezes exacerbado, caso ocorra a ruptura de estruturas císticas intrateciduais, não denotando, ao mesmo tempo, características específicas de cada lesão (RADIN; WELLMAN, 2001; GOLDSCHIMIDT; GOLDSCHIMIDT,
2017).

Assim, corroborando com o observado aqui em análise histopatológica, a literatura sustenta que são características da lesão apresentada o seu caráter demarcado, de maneira isolada da pele, internamente formado por intensa reação fibrosa que entremeia regiões hipertróficas de anexos foliculosebáceos desorganizados (GOLDSCHIMIDT; GOLDSCHIMIDT, 2017).

Por estas razões, o exame histopatológico foi de fundamental importância para o diagnóstico do caso descrito, já que este consiste da análise da arquitetura tecidual e relação das suas estruturas (MOTOSUGI et al., 2001), permitindo igualmente excluir a hipótese neoplásica neste estudo, além de fundamentar que a inflamação e a hemorragia observadas na análise citológica eram consequentes do processo principal de proliferação fibroanexial e manipulação tecidual em colheita de material, respectivamente.

Recomenda-se, portanto, a confirmação histopatológica, considerando que muitas vezes o diagnóstico definitivo de determinada proliferação cutânea depende da identificação da linha epitelial de revestimento ou mesmo da estrutura da qual se originou a formação (MAXIE, 2016), sendo impossível essa determinação por meio citológico com tamanha riqueza e precisão.

\section{Conclusão}

Os achados macro e microscópicos foram determinantes para o diagnóstico da lesão como hamartoma fibroanexial, sendo necessário o exame histopatológico para estudo minucioso e conclusivo do quadro. Adicionalmente, novos estudos ainda precisam ser realizados no intuito de determinar criteriosamente a epidemiologia do processo, bem como para que se conheçam os fatores que realmente influenciam no aparecimento da lesão e seus fatores de proteção, se existentes.

\section{Referências}

BORGES, I. L. et al. Diagnóstico citopatológico de lesões palpáveis de pele e partes moles em cães. Revista Brasileira de Higiene e Sanidade Animal, v. 10, n. 3, p. 382-395, 2016.

BOYLE, M. H.; HILL, G. D. Non neoplastic Lesions Atlas: Skin - Fibroadnexal hamartoma. Disponível em: $<$ http://ntp.niehs.nih.gov/nnl/integumentary/skin/hamarto/ index.htm>. Acesso em: 10 out. 2014.

CHIKWETO, A. et al. Neoplastic and nonneoplastic cutaneous tumors of dogs in Grenada, West Indies.

International Scholarship Research Notices Veterinary Science, p. 1-7, 2011.

COWELL, R. L. et al. Diagnóstico citológico e hematologia de cães e gatos. 3 ed. São Paulo: Medvet, 2009. 476p.

EL-DAROUTY, M. A. et al. Folliculo-sebaceous cystic hamartoma. International Journal of Dermatology, v. 40, n. 7, p. 454-457, 2001. 
GOLDSCHMIDT, M. H.; GOLDSCHMIDT, K. H. Epithelial and melanocytic tumors of the skin. In: MEUTEN, D. J. Tumors in domestic animals. 5.ed. Ames: Iowa State, 2017. p.88-141.

GOLDSCHMIDT, M. H.; SHOFER, F.S. Skin tumors of the dog and cat. U.K.: Pergamon, 1992. 316p.

GROSS, T. L. et al. Skin diseases of the dog and cat: Clinical and histopathologic diagnosis: Blackwell Science, 2005. 937p.

GROSS, T. L.; IHRKE, P. J.; WALDER, E. J. Veterinary dermatopathology: a macroscopic and microscopic evaluation of canine and feline skin disease. St. Louis: Mosby, 1992. 520p.

JOYCE, J. Notes on Small Animal Dermatology. 1. ed. Oxford: Wiley-Blackwell, 2010. 768p.

KIEHL, A. R.; MAYS, M. B. C. Atlas for the diagnosis of tumors in the dog and cat: WILEY Blackwell, 2016.

LIN, Y. C.; TSAI, T. F. Folliculosebaceous Cystic Hamartoma - Report of a case. Dermatologica Sinica, v. 18 , p. 341-345, 2000.

LOURES, F. H. Nevos Anexiais Em Cães: Aspectos clínicos e histopatológicos em $\mathbf{6 1}$ casos. Viçosa, 2005. 46f. Dissertação (Magister Scientiae). Programa de PósGraduação em Medicina Veterinária, Universidade Federal de Viçosa, 2005.

LOURES, F. H.; CONCEIÇÃO, L. G. Nevi and cutaneous hamartomas in dogs: retrospective clinical and epidemiologic study of 81 cases. Ciência Rural, v. 39, p. 2527-2532, 2009.

MAXIE, M. G. Jubb, Kennedy, and Palmer's pathology of domestic animals: Volume 1. Elsevier, 2016. 798p.

MEIRELES, L. V. et al. Levantamento epidemiológico de dermatopatias em pequenos animais. IN: Congresso Fluminense de Iniciação Científica e Tecnológica, 5., 2013, Campos dos Goytacazes. Anais...Campos dos Goytacazes: Essentia Editora, 2013.

MEDEIROS, V. B. et al. Hamartoma colagenoso cutâneo em um paciente canino. MEDVEP Dermatologia, v. 3, n. 8, p. 73-74, 2014.

MILLER, W. H.; GRIFFIN, C. E.; CAMPBELL, K. L. Neoplastic and Non-Neoplastic Tumors. Muller and Kirk's Small Animal Dermatology. 7. ed. Missouri: Elsevier Mosby, 2013. 948p.

MOTOSuGi, U. et al. Small Animal Oncology. Blackwell Science, Oxford, 2001.

PEREIRA, E. B. et al. Atlas brasileiro de energia solar. São José dos Campos: INPE, 2006. 60p. ISBN 978-85-17-
00030-0.

RADIN, M. J.; WELLMAN, M. L. Interpretation of canine and feline cytology. 2.ed. Gloyd Group Inc., 2001. $92 \mathrm{p}$.

RASKIN, E. R.; MEYER, D. J. Atlas de citologia de cães e gatos. 2.ed. Rio de Janeiro: Elsevier, 2011. 472p.

SCOTT, D. W.; MILLER, W. H.; GRIFFIN, C. E. Muller \& Kirk's Small Animal Dermatology. 6. ed. St. Louis: SAUNDERS, 2001. 1527p.

SIPOS, W. et al. Fibroepithelial hamartoma in a domestic pig. Veterinary pathology, v. 44, p. 411-413, 2007.

TIMM, L. L. Técnicas rotineiras de preparação e análise de lâminas histológicas. Caderno La Salle XI, v. 2, n. 1, p. 231-239, 2005. 